\title{
Possible solar modulation of the equatorial quasi-biennial oscillation: Additional statistical evidence
}

\author{
Boris E. Soukharev ${ }^{1}$ and Lon L. Hood \\ Lunar and Planetary Laboratory, University of Arizona, Tucson, Arizona
}

\begin{abstract}
Although the quasi-biennial oscillation (QBO) in the equatorial zonal wind is dominantly driven by wave forcing originating in the troposphere, a recent study suggests that certain properties of the QBO may vary slightly on the 11-year solar cycle timescale [Salby and Callaghan, 2000]. Here we report further statistical investigation using both equatorial wind data for levels from 50 to $1 \mathrm{hPa}$ and longterm proxy solar ultraviolet flux time series $(10.7-\mathrm{cm}$ solar radio flux and sunspot numbers). Spectral analysis of the solar time series yields evidence for a significant spectral peak at periods between 25 and 30 months, approximately equivalent to the mean QBO period, as had also been noted by earlier authors [Shapiro and Ward, 1962]. Cross-spectral analysis of the $10.7-\mathrm{cm}$ solar radio flux and equatorial zonal wind time series shows significant coherency at the QBO period at all available pressure levels. The phase lag of the wind data relative to the solar flux at the QBO period ranges from $0-1$ months near the stratopause $(1 \mathrm{hPa})$ to $20-24$ months in the lower stratosphere $(50 \mathrm{hPa})$. The nearly inphase relationship near the stratopause suggests a possible modulation of the QBO at this level by the radiative and photochemical effects of solar ultraviolet variations. The amplitudes of the solar variations at the QBO period tend to be larger under solar maximum than under solar minimum conditions. Composite analysis of the westerly and easterly phases of the equatorial zonal wind shows subtle but consistent differences in the durations of the westerlies and easterlies between solar maximum and minimum conditions.
\end{abstract}

\section{Introduction}

Labitzke [1987] and Labıtzke and van Loon [1988] originally discovered a signature of the 11-year solar cycle in polar stratospheric temperatures stratified according to the easterly or westerly phase of the equatorial quasi-biennial oscillation (QBO). Since that time this possible solar-QBO-stratosphere/troposphere relationship has been intensively investigated in numerous observational and modeling studies [e.g., Baldwin and Dunkerton, 1989; Hamilton, 1990; Kodera, 1993; Haigh, 1994; Rind and Balachandran, 1995; Naito and Hirota, 1997; Shindell et al., 1999; Soukharev, 1999; van Loon and Labitzke, 2001]. Results show that under solar minimum conditions the stratospheric polar vortex is weaker and warmer during the easterly QBO phase than during the westerly QBO phase, because of favorable dynamical conditions for planetary waves to propagate poleward and disturb the vortex from its

\footnotetext{
${ }^{1}$ Also at Department of Climatology, St. Petersburg State University, St. Petersburg, Russia.

Copyright 2001 by the American Geophysical Union.

Paper number 2001JD900095.

0148-0227/01/2001JD900095\$09.00
}

radiative equilibrum. This is in agreement with the dynamical theory of the equatorial QBO [Holton and Tan, 1980, 1982; O'Sullivan and Salby, 1990; Tung and Yang, 1994]. However, in contrast to this theory, under solar maximum conditions the polar vortex tends to be weaker and warmer during QBO westerlies than during QBO easterlies.

To date, no completely viable physical mechanism has been proposed which can satisfactorily explain the observed "switch" of sign of the relationship between the equatorial QBO and the extratropical stratosphere from solar minimum to maximum. As originally speculated by Hines [1974], one possible mechanism for transmission of solar-induced perturbations in the zonal mean dynamics from the upper stratosphere downward is a modification of properties of upwardly propagating planetary waves. Indeed, recent general circulation model (GCM) experiments [e.g., Haigh, 1994; Shındell et al., 1999] show that UV absorption changes the upper stratospheric zonal wind, which in turn affects planetary wave propagation and hence circulation in both the stratosphere and troposphere. However, the amplitudes of the modeled variations in both the upper and lower stratosphere were significantly less than those estimated observationally. Similarly, although GCM experiments involving a simulated equatorial QBO, con- 
ducted by Balachandran and Rind [1995] and Rind and Balachandran [1995], were able to show significant consequences of solar-induced changes in the upper stratospheric zonal wind extending down to the troposphere, these experiments employed unrealistically large solar UV forcing as compared to the observed 11-year solar cycle. Nevertheless, these GCM experiments demonstrated that the equatorial QBO might have played a significant role in modulating the impact of solar variability on the stratosphere and troposphere.

In a recent paper, Salby and Callaghan [2000] suggest that the observed solar signature in stratospheric records grouped according to QBO phase may be caused, at least in part, by an 11-year solar cycle modulation of the equatorial QBO itself. In particular, they find that the duration of the westerly QBO phase in the middle stratosphere varies with a systematic pattern resembling the curve of the 11-year solar cycle. Because of the major role of the QBO in determining interannual variability of the stratosphere, such a modulation, if present, could significantly assist in explaining the unexpectedly large amplitudes of apparent solar cycle variations in the equatorial stratosphere [Hood et al., 1993; Chandra and McPeters, 1994; McCormack and Hood, 1996; Hood, 1997] as well as the polar stratospheric signal discovered by Labitzke and van Loon [1988].

In the present study, we apply cross-spectral analysis to the solar and equatorial zonal wind data and report new statistical evidence for a decadal modulation of the equatorial QBO. In particular, we show that long-term proxies for solar ultraviolet flux contain a significant oscillation at periods between 25 and 30 months, approximately equivalent to the mean QBO period, and that the amplitude of this solar spectral component tends to be larger under solar maximum than under solar minimum conditions. We also report cross-spectral analyses demonstrating significant coherency between the solar flux and equatorial zonal wind time series over the 1957-1999 time period. In section 2 we describe the data and spectral analysis method used. In section 3 we discuss the observed decadal variability of the equatorial QBO. In section 4 we investigate the presence of a 25-30-month spectral peak in different solar flux proxy records. In section 5 , the mean squared coherency and phase lags between the solar flux and equatorial zonal wind time series are calculated. Finally, in section 6 a composite analysis of the equatorial zonal wind is performed for the case of possible 11-year solar forcing. We demonstrate that mean vertical profiles of the equatorial westerlies and easterlies are different between solar minimum and maximum conditions.

\section{Data and Method of Analysis}

We use monthly mean data of the equatorial zonal wind at $50,40,30,20$, and $10 \mathrm{hPa}$ from the Free University of Berlin (B. Naujokat, personal communication, 2000), for the period from January 1957 to December

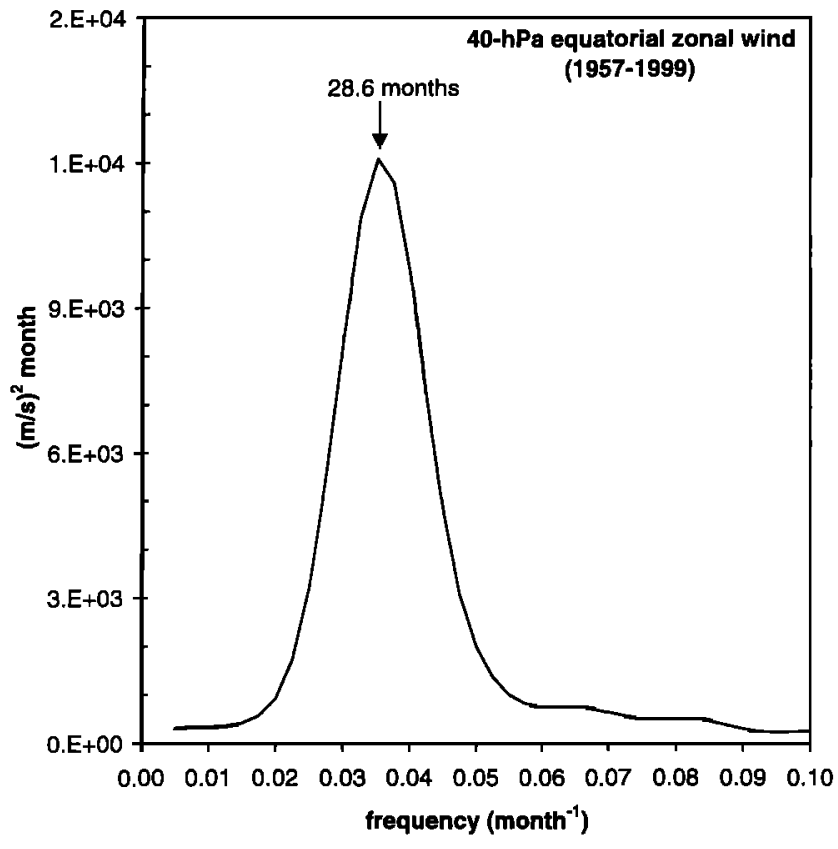

Figure 1. Autospectrum of the $40-\mathrm{hPa}$ equatorial zonal wind. Data for the period from January 1957 to December 1999 are used for the calculation. The number of degrees of freedom (DOF) is 19 . The $95 \%$ confidence limits are $[0.57,2.10]$, multiplied by an autospectral estimate. The spectral peak is significant at the $95 \%$ confidence limit. Read $2 . \mathrm{E}+04$ as $2 \times 10^{4}$.

1999, obtained from radiosonde data at Canton (19561967), Gan (1968-1975), and Singapore (1976-1999). For example, Figure 1 represents an autospectral estimate of the equatorial zonal wind at $40 \mathrm{hPa}$. The spectrum exhibits a relatively wide peak at frequencies corresponding to a period of $\sim 27-29$ months, with the highest value of spectral density observed at the periods between 28 and 29 months. It is noteworthy that when the equatorial QBO was discovered by Ebdon [1960] and Reed et al. [1961], it was believed to be an oscillation with a dominant period of $\sim 26$ months. Later analyses of longer time records showed that the QBO period actually varies from 22 to 34 months, with an average of slightly more than 28 months [Baldwin et al., 2001].

On the basis of monthly geopotential height data at 5,2 , and $1 \mathrm{hPa}$ from the National Center for Environmental Prediction (NCEP) (S. Zhou, personal communication, 1999) we have also calculated equatorial zonal wind at these levels for the period from January 1980 to December 1997, using a curvature approximation of the gradient wind equation [e.g., Randel, 1992]. Power spectra for these upper levels (not given here) also exhibit prominent peaks near the QBO period, although at 1 and $2 \mathrm{hPa}$ the variance corresponding to the annual and especially to the semiannual oscillations becomes even larger than that corresponding to the QBO period.

The solar data used in this study are monthly mean values of the $10.7-\mathrm{cm}$ solar radio flux (in $10^{-22} \mathrm{~W} \mathrm{~m}^{-2}$ 
$H z^{-1}$ ) for the period from February 1949 to December 1999, received from the World Data Center for Solar-Terrestrial Physics in Boulder, Colorado. In addition, monthly mean data of Zurich sunspot numbers for the period from 1800 to 1999 , received from the same source, are used. As is well known, these time series, especially the $10.7-\mathrm{cm}$ flux, correlate closely with solar ultraviolet variations at wavelengths important for ozone photochemistry and radiative heating in the upper stratosphere.

As a tool for the investigation, we use cross-spectral analysis carried out according to Jenkins and Watts [1968]. Spectra of different kinds (autospectra, cross spectra, coherency spectra, and phase spectra) have been estimated. For the smoothing of spectral estimates the Parzen spectral window was used, as this window yields a minimum variance as compared to other widely used spectral windows [Jenkins and Watts, 1968]. Use of the Parzen window leads to a spectral bandwidth of $b=1.86 / L \mathrm{~m}^{-1}$, where $L$ is the lag (in months) chosen for autospectral and cross-spectral estimates. When a time series contains $N$ monthly values, degrees of freedom DOF $=2 b N$ are associated with the spectral estimate. The confidence limit of the squared coherency estimate, $K^{2}$, has been obtained from the confidence limit of $\operatorname{arctanh}(|K|)$, given by $c= \pm r /$ DOF $^{1 / 2}(r=$ 1.96 for the $95 \%$ confidence limit). The $95 \%$ confidence limits for autospectral and phase estimates have been obtained from the corresponding diagrams after Jenkıns and Watts [1968].
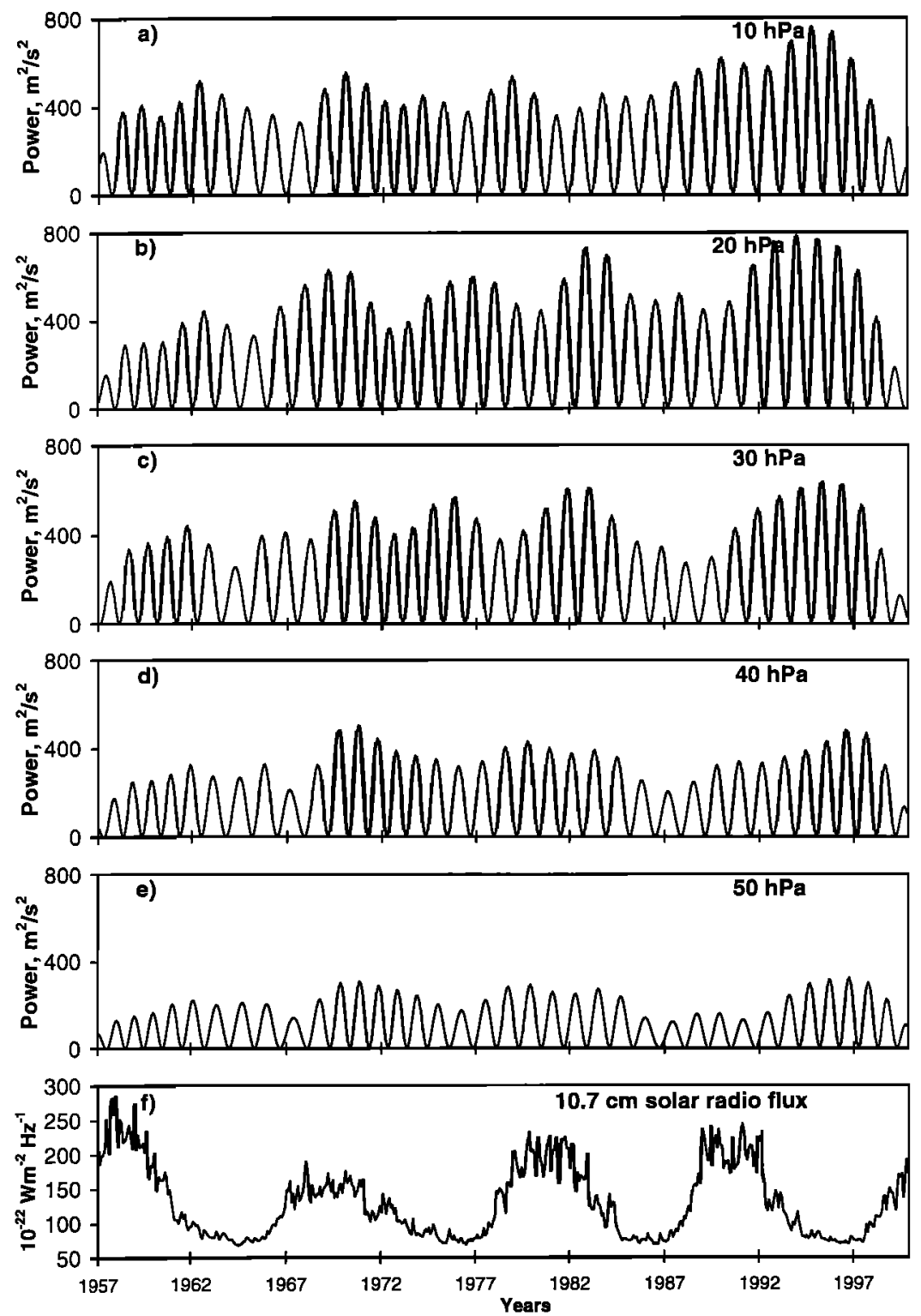

Figure 2. Time-dependent power (squared speed) of the band-pass-filtered (frequency bounds corresponding to periods of 39 and 20 months) equatorial zonal wind at (a) $10 \mathrm{hPa}$, (b) $20 \mathrm{hPa}$,(c) $30 \mathrm{hPa}$, (d) $40 \mathrm{hPa}$, and (e) $50 \mathrm{hPa}$. (f) The $10.7-\mathrm{cm}$ solar radio flux. 


\section{Decadal Modulation of the QBO in the Equatorial Zonal Wind}

Salby and Callaghan's [2000] analysis of the filtered record of the equatorial zonal wind containing only the variance at periods in the range beween 35.3 and 19.3 months has yielded evidence for a decadal modulation of the equatorial zonal wind near $45 \mathrm{hPa}$. The range between 35.3 and 19.3 months was chosen because the periodogram calculated on the data of the $45-\mathrm{hPa}$ equatorial zonal wind for the period from 1956 to 1996 showed a maximum variance in this range [Salby and Callaghan, 2000, Figure 1b].

In our study, in accordance with Figure 1 demonstrating that most of the variance in the equatorial zonal wind data occurs at periods between $\sim 39$ and 20 months, we use a band-pass filter with corresponding frequency bounds in order to isolate variability associated with the QBO. Such a filtering procedure leads to a suppression of periodicities $>39$ months and $<20$ months, whereas the quasi-biennial periodicity between 25 and 30 months remains unchanged. Periods in the vicinity of the chosen frequency bounds, i.e. 33-39 months and 20-24 months, are also slightly suppressed.
Figure 2 shows plots of time-dependent power (squared speed) of the band-pass-filtered equatorial zonal wind for levels between 10 and $50 \mathrm{hPa}$ and a plot of the $10.7-\mathrm{cm}$ solar radio flux. At all of these levels some signs of decadal variation are visible, but the decadal variation at 40 and $50 \mathrm{hPa}$ tends to correlate approximately with extrema of the solar cycle, with about a 1-2-year phase lag after the solar extrema, except during the last decade. This is the result achieved by Salby and Callaghan [2000], who obtained evidence for an inphase correspondence between the time-dependent power of the $45-\mathrm{hPa}$ zonal wind and the 11-year solar cycle. Subsampling the band-pass-filtered record by only January- February data, they also noticed that the corresponding January-February QBO power reached a maximum 1-2 years after each solar maximum, except during the last decade.

One should mention, however, that our experiments, with slightly different frequency bounds of the bandpass filter used, have shown that the position (i.e., the shift along the time axis) of extrema of the power for all levels is sensitive to even small changes of the frequency bounds (e.g., the use of 35 and 22 months instead of 39 and 20 months). Therefore care must be taken when in-
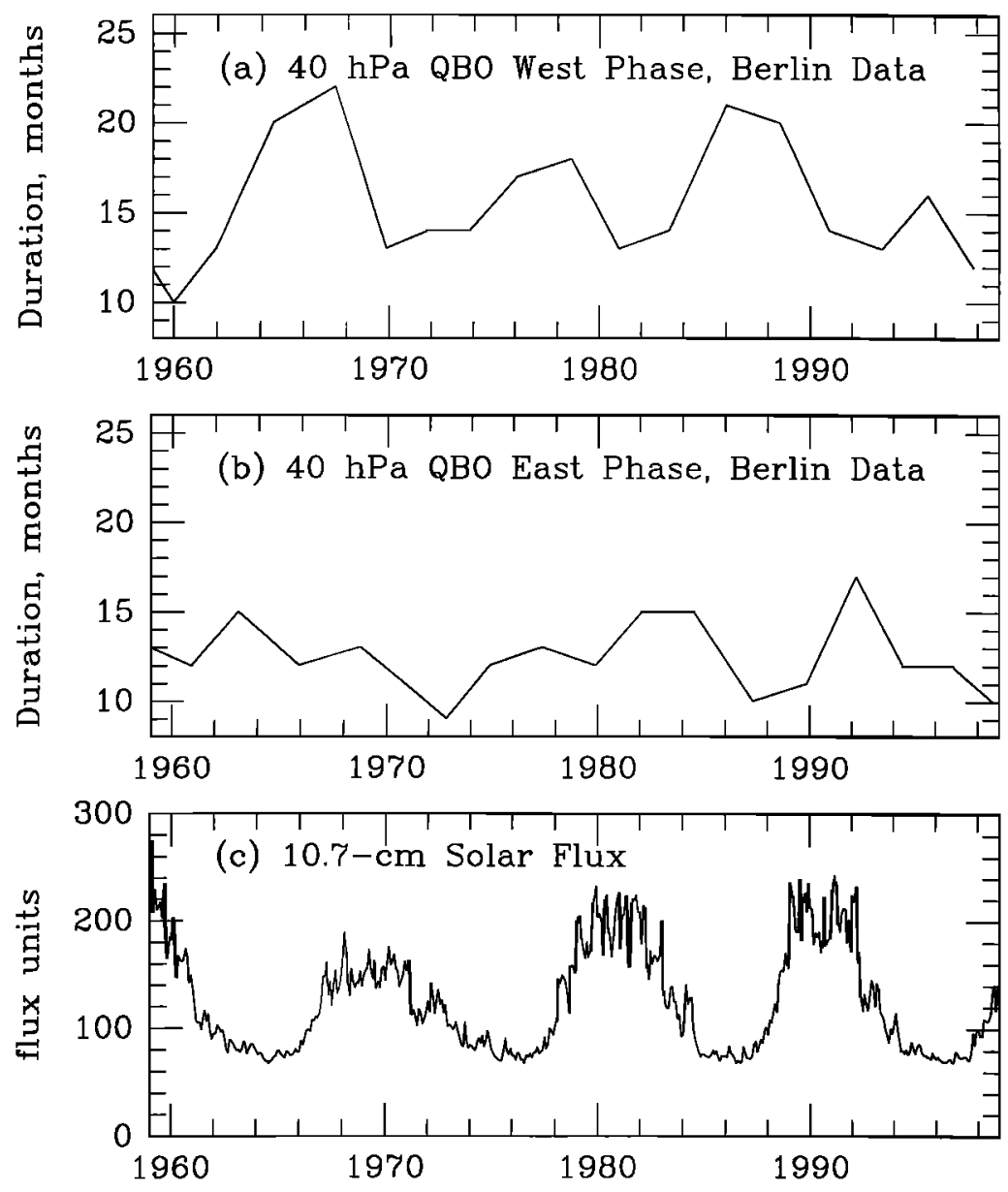

Figure 3. Duration of equatorial (a) westerlies and (b) easterlies at $40 \mathrm{hPa}$ as a function of year compared with (c) the 10.7-cm solar flux. 

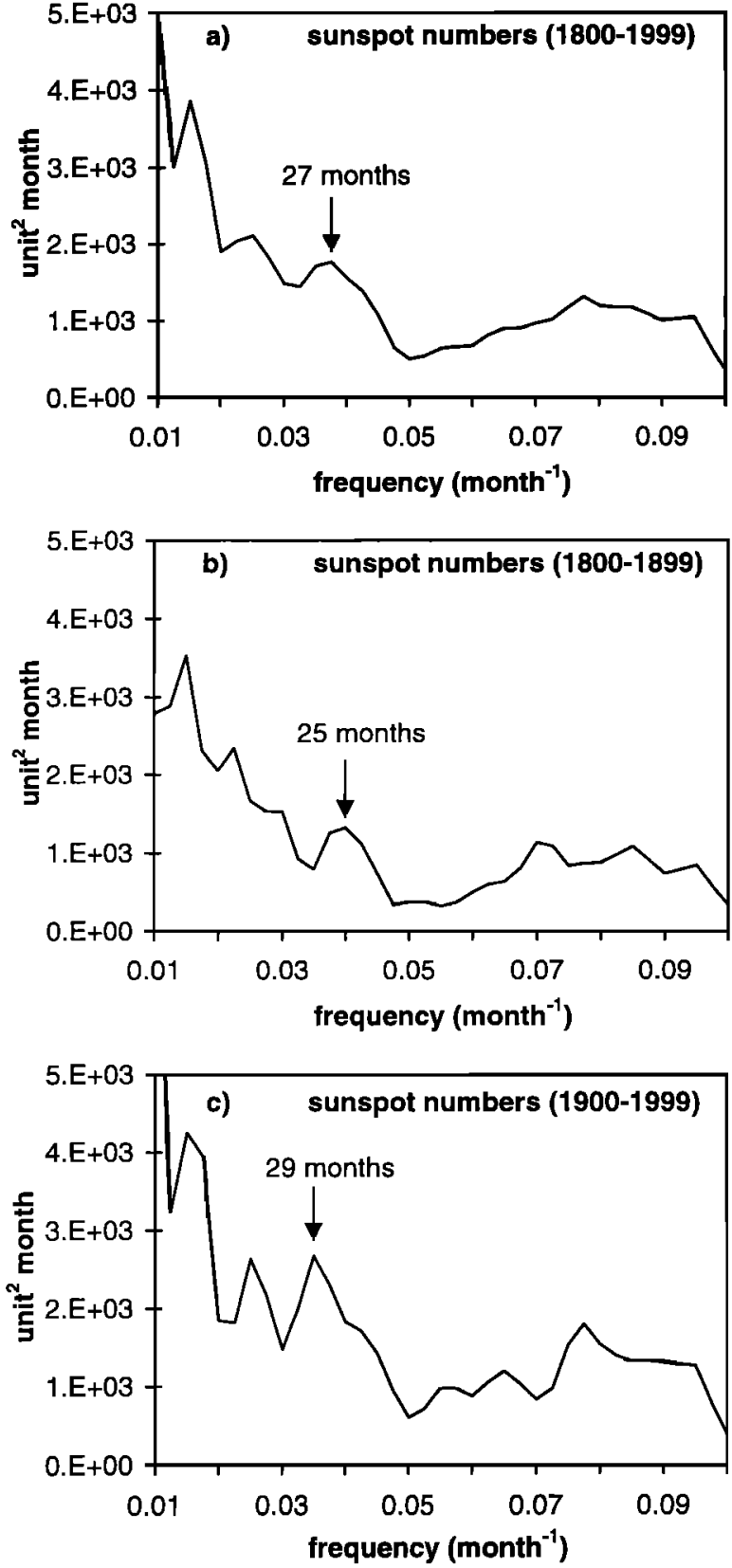

Figure 4. Autospectral estimates of monthly Zurich sunspot numbers for the periods from (a) January 1800 to December 1999 (b) January 1800 to December 1899, and (c) January 1900 to December 1999, after subtracting a moving average with a window width equal to 41 months. The number of degrees of freedom is 35 in Figure $4 \mathrm{a}$ and 17 in Figures $4 \mathrm{~b}$ and $4 \mathrm{c}$. The $95 \%$ confidence limits are $[0.65 ; 1.70]$ in Figure $4 \mathrm{a}$ and $[0.57$; $2.24]$ in Figures $4 \mathrm{~b}$ and $4 \mathrm{c}$, multiplied by an autospectral estimate. All three spectral peaks corresponding to the 25-29-month periodicity are significant at the $95 \%$ confidence level.

terpreting the correspondence between extrema of the power of the equatorial zonal wind and of the solar cycle. One may say only that there is a tendency for such a correspondence. Regardless of the choice of frequency bounds applied for the filtering procedure, a decadal- scale modulation of the equatorial zonal wind is seen in all experiments.

Figure 3 shows line graphs of the duration of equatorial westerlies and easterlies at $40 \mathrm{hPa}$. In agreement with the results of Salby and Callaghan [2000] it is seen that the duration of equatorial westerlies appears to vary approximately inversely with the solar cycle. As compared with their analysis, in the present study we find a decadal variation of westerlies over an extended period up to the end of 1999. As seen in Figure 3b, the duration of easterlies at $40 \mathrm{hPa}$ does not show a good correspondence with the solar cycle.

\section{Solar Variability on the QBO Timescale}

During the early 1960s, Shaptro and Ward [1962] reported a possible peak in the solar activity spectrum corresponding to a period of $\sim 25$ months. Their study was based on an analysis of a 200-year (1756-1955) record of monthly Zurich relative sunspot numbers. Statistical tests showed this 25-month spectral peak to be significant at the $95 \%$ confidence level. When the record was divided into two series of 100 -years length each (1756-1855 and 1856-1955), a significant spectral peak corresponding to the 25 -month periodicity was found in both series. The paper by Shapiro and Ward appeared just after the reports about discovery of the QBO in the equatorial stratospheric zonal wind [Ebdon, 1960; Reed et al., 1961], and the authors speculated that periodic variations of solar output might be responsible for driving the QBO itself. Since that time it has been shown by many studies that the equatorial $Q B O$ is an internal oscillation driven from the troposphere [e.g., Lindzen and Holton, 1968; Holton and Lindzen, 1972; Plumb, 1977; Lindzen, 1987]. Nevertheless, the existence of a solar oscillation with a period approxi-

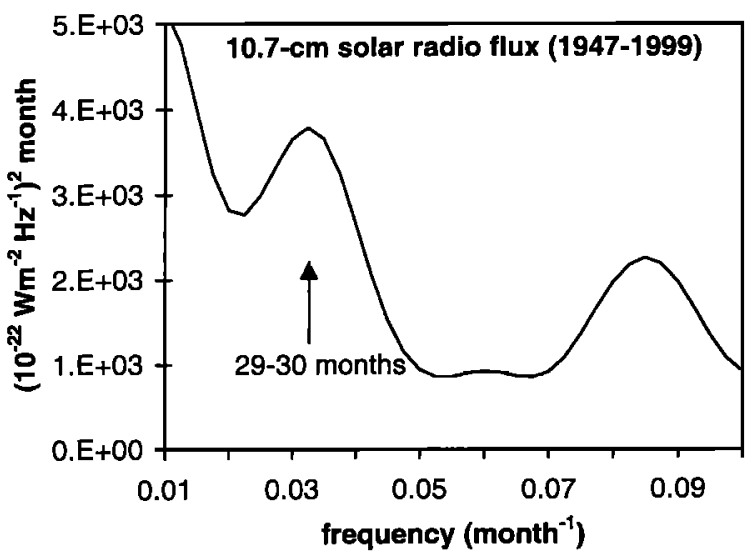

Figure 5. Autospectral estimates of the monthly 10.7cm solar radio flux for the period from February 1947 to December 1999 after subtracting a moving average with a window width equal to 41 months. The number of degrees of freedom is 22 . The $95 \%$ confidence limits are $[0.59 ; 1.98]$, multiplied by an autospectral estimate. 

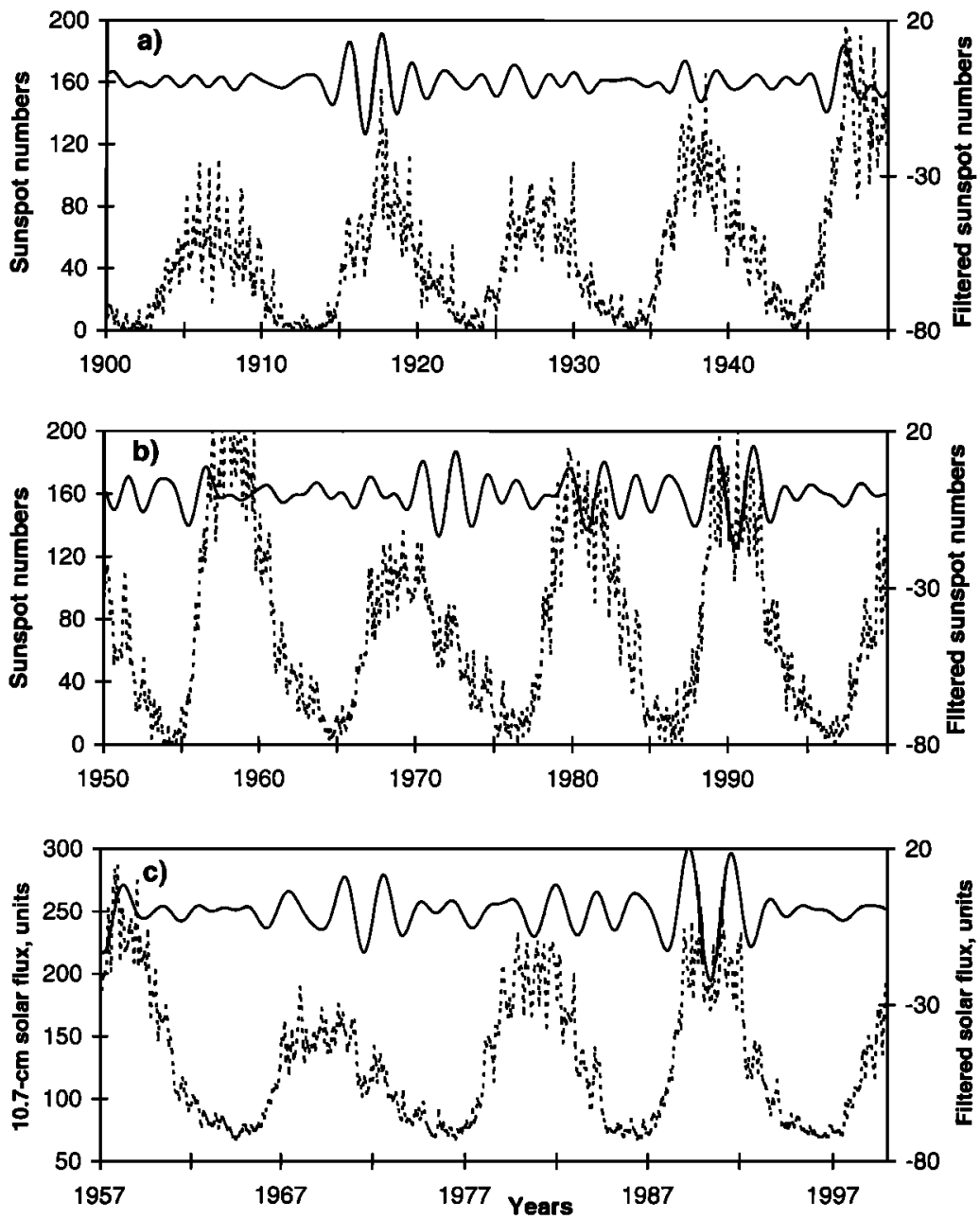

Figure 6. Raw (dashed line) and band-pass-filtered (with frequency bounds $[0.0256 ; 0.05]$ ) (solid line) sunspot number time series for the periods from (a) January 1900 to December 1949 and from (b) January 1950 to December 1999 and the (c) 10.7-cm solar radio flux for the period from January 1957 to December 1999.

mately equal to that of the equatorial QBO is of interest, especially in light of the recent finding by Salby and Callaghan [2000] that the equatorial QBO may vary slightly with the 11-year solar cycle.

In the present study we analyze both monthly data of the Zurich relative sunspot numbers for the last 200 years and of the 10.7-cm solar radio flux for the period since 1949 , when the radio flux data became available. Figure 4 shows the autospectral estimates of sunspot numbers, obtained after subtracting a moving average with a window width of 41 months. After removal of the predominant 11-year periodicity the residual spectrum of sunspot numbers contains a few other secondary periodicities (their amplitudes are $\sim 2$ orders of magnitude less than that of the 11-year solar oscillation) in the frequency range between 0.01 and 0.10 month $^{-1}$. Among these are the 5-6-year oscillation (which is likely the second harmonic of the 11-year solar cycle), the 40 50-month oscillation, and the 25-29-month periodicity. The latter spectral peak is significant at the $95 \%$ confidence level for all three time intervals shown in Figure
4. Comparison of Figures $4 \mathrm{~b}$ and $4 \mathrm{c}$ shows that the mean period of this spectral peak is near 25 months in the nineteenth century and shifts to $\sim 29$ months in the twentieth century. Analysis of the full 200-year record of sunspot numbers yields a mean spectral peak at a period of $\sim 27$ months.

The 10.7-cm solar radio flux is known to be a useful proxy for solar ultraviolet variability at wavelengths important for ozone formation and radiative heating in the upper stratosphere. Figure 5 represents autospectral estimates of the $10.7-\mathrm{cm}$ solar radio flux calculated from the available data since 1949. The estimates in Figure 5 are more smoothed than in Figure 4c because of the smaller length of the time series analyzed and, consequently, lower spectral resolution. Nevertheless, Figure 5 also exhibits a significant spectral peak centered at a period of $\sim 29-30$ months. In addition to statistical criteria of significance, similarity of the patterns in Figures $4 \mathrm{c}$ and $5 \mathrm{can}$ be an additional argument in favor of the existence of a 25-30-month periodicity in the $10.7-\mathrm{cm}$ flux time series. 

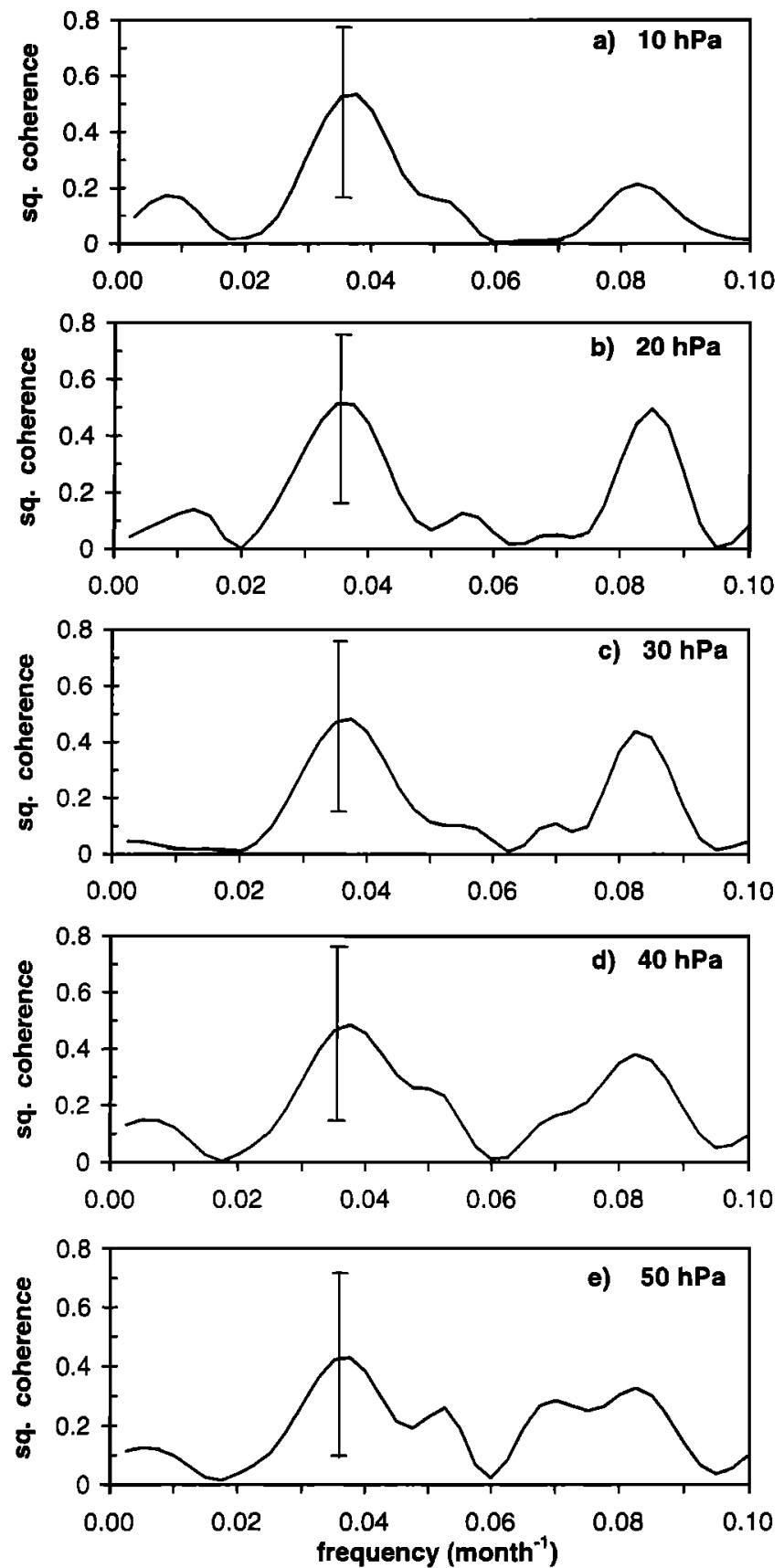

Figure 7. Squared coherency estimates of the $10.7-\mathrm{cm}$ solar radio flux with the equatorial zonal wind at (a) $1 \mathrm{hPa}$, (b) $2 \mathrm{hPa}$, (c) $5 \mathrm{hPa}$. Data for the period from January 1957 to December 1999 are used. From all data a moving average with a window width of 41 months has been subtracted. For all the estimates the number of degrees of freedom equals 18 . The $95 \%$ confidence intervals are shown for the frequency 0.035 month $^{-1}$, which corresponds to a period of 28.6 months

In order to isolate the variance associated with the 25-30-month oscillation the time series of sunspot numbers and of the $10.7-\mathrm{cm}$ solar radio flux were filtered using a band-pass filter with frequency bounds corresponding to periods of 39 and 20 months. The same filtering procedure was applied to the raw data of the equatorial zonal wind. As seen in Figure 6, which compares time series of the raw and band-pass-filtered sunspot number data, the filtered time series exhibit a decadal modulation such that the amplitude of the filtered time series is larger under solar maximum conditions than under solar minimum conditions. On the average, at solar minimum the $25-30$-month solar oscillation is weak or even almost nonexistent, as in the cases of the 1910-1914, 1932-1936, 1962-1966, and 19941999 intervals. On the contrary, at solar maximum the 25-30-month solar oscillation is usually strong, sometimes with a slight phase lag after maximum of the 11year solar cycle, as in the case of 1970-1974.

\section{Possible Interaction Between Solar Variability and Equatorial Zonal Wind on the Timescale of the QBO}

In section 4, evidence was obtained for a 25-30-month secondary spectral peak in two different proxy records of solar ultraviolet flux (Figures 4 and 5). This 2530-month solar spectral peak is modulated in amplitude with larger values under solar maximum conditions
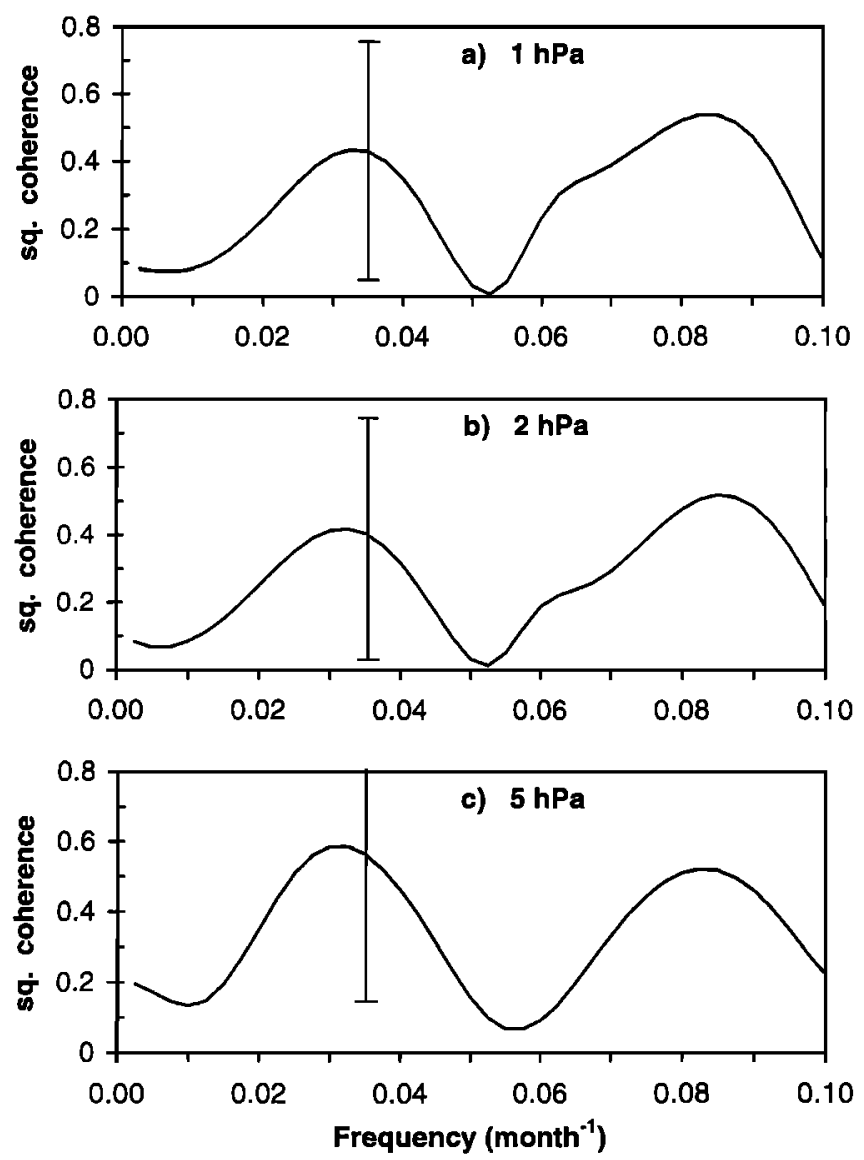

Figure 8. Same format as for Figure 7 but for the equatorial zonal wind at (a) $1 \mathrm{hPa}$, (b) $2 \mathrm{hPa}$, and (c) 5 $\mathrm{hPa}$. Data for the period from January 1980 to December 1997 are used. For all the estimates the number of degrees of freedom equals 12 . The $95 \%$ confidence limits are shown for the frequency 0.035 month $^{-1}$, which corresponds to a period of 28.6 months. 

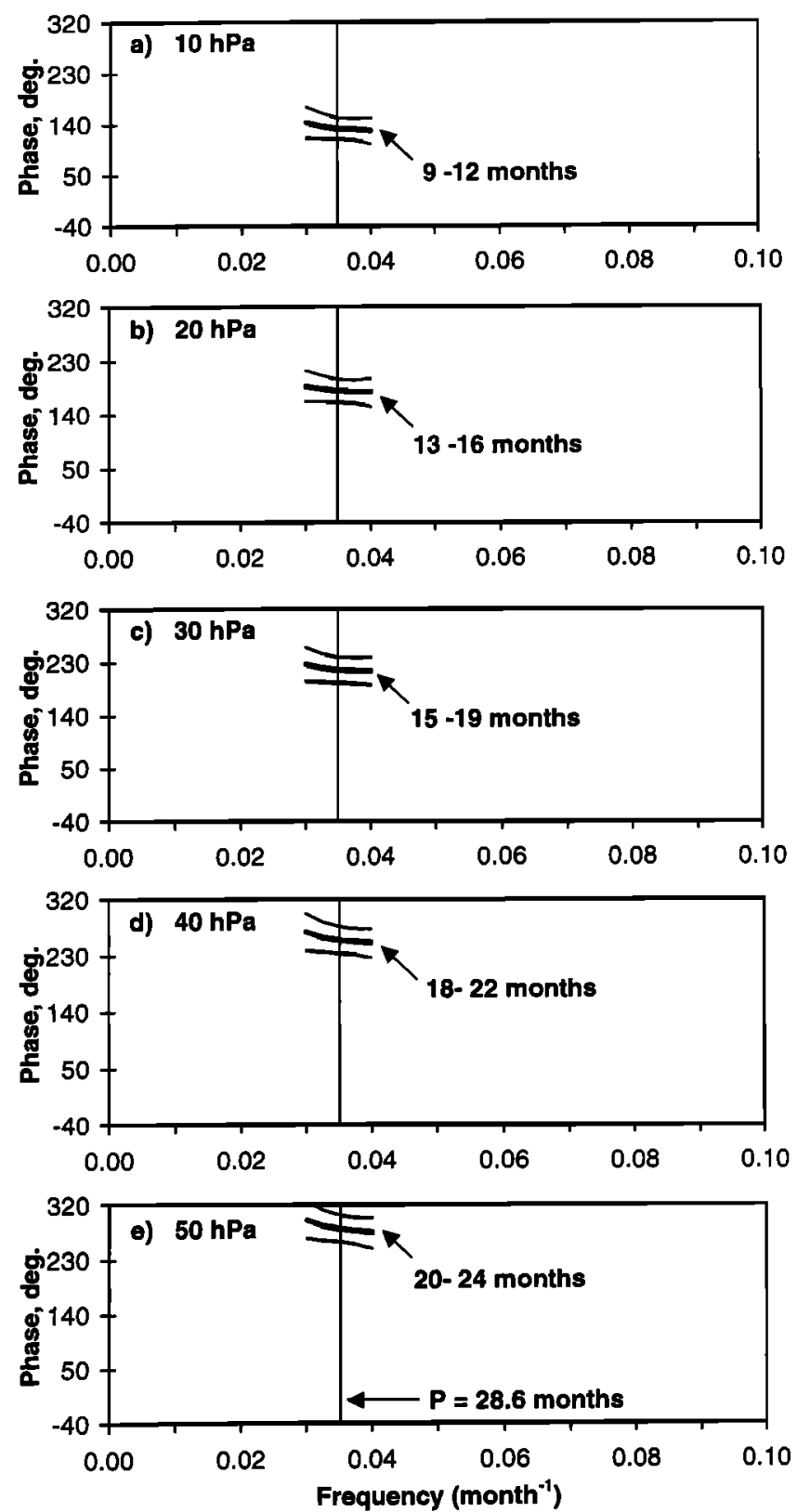

Figure 9. Phase estimates of the $10.7-\mathrm{cm}$ solar radio flux with the equatorial zonal wind at (a) $10 \mathrm{hPa}$, (b) $20 \mathrm{hPa}$, (c) $30 \mathrm{hPa}$, (d) $40 \mathrm{hPa}$, and (e) $50 \mathrm{hPa}$. Data for the period from January 1957 to December 1999 are used. From all data a moving average with a window width of 41 months was subtracted. The vertical line indicates a frequency of $0.035 \mathrm{month}^{-1}$, which corresponds to a period of 28.6 months. The thick line represents a phase lag of a response of the zonal wind to an hypothesized solar signal. Two thin lines represent $95 \%$ confidence limits.

than under solar minimum conditions (Figure 6). In order to investigate a possible response of the QBO in the equatorial zonal wind to the $25-30$-month solar oscillation, cross-spectral analyses of the $10.7-\mathrm{cm}$ flux versus equatorial zonal wind time series have been carried out. In the middle and lower stratosphere $(10-50 \mathrm{hPa})$ the radiosonde-derived Berlin record was employed for the
1957-1999 time interval. In the upper stratosphere (5, 2 , and $1 \mathrm{hPa}$ ) we have analyzed equatorial zonal wind calculated from NCEP geopotential height data for the period from January 1980 to December 1997. Figure 7 shows the estimates of the squared coherency of the $10.7-\mathrm{cm}$ solar radio flux, with the equatorial zonal wind from 10 to $50 \mathrm{hPa}$, for the period from 1957 to 1999 . Figure 8 shows similar estimates for the $1-5-\mathrm{hPa}$ pressure range for the period from 1980 to 1997 . In the latter case the shorter time series length leads to a lower spectral resolution, which in turn yields a slight frequency shift of the peaks seen, for instance, in Figure $8 \mathrm{c}$. Nevertheless, despite the difference in spectral resolution between Figures 7 and 8 , all estimates of squared coherency for all levels show the same pattern: The coherency spectrum exhibits a prominent peak at a period of 25-30 months (the secondary peak visible in the frequency range between 0.0825 and 0.0875 month $^{-1}$ represents a possible interaction between solar variability and zonal wind on the 12-month timescale). At all levels from the upper to the lower stratosphere, the coherency estimates corresponding to the $25-30$-month period are significant at the $95 \%$ confidence level.

Figures 9 and 10 show phase estimates corresponding to the coherency spectra of Figures 7 and 8 . These phase estimates indicate a dependence on altitude of
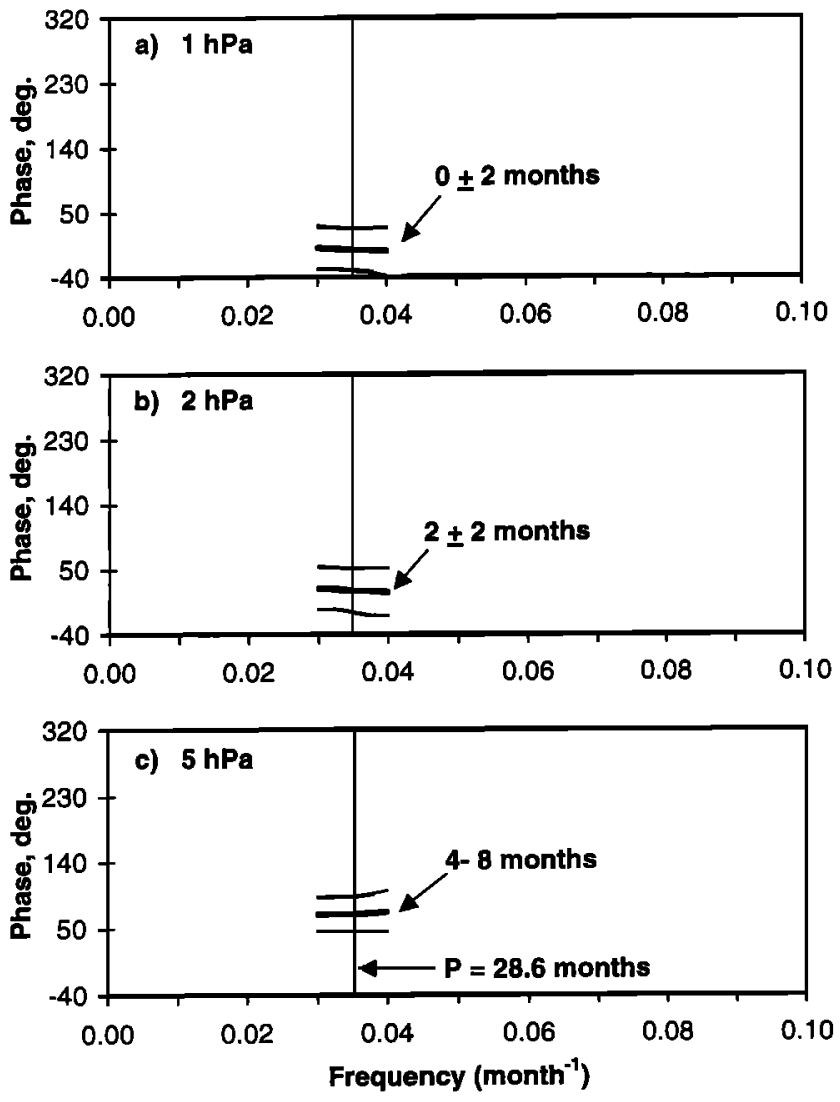

Figure 10. Same format as for Figure 9 but for the equatorial zonal wind at (a) $1 \mathrm{hPa}$, (b) $2 \mathrm{hPa}$, (c) $5 \mathrm{hPa}$. Data for the period from January 1980 to December 1997 are used. 


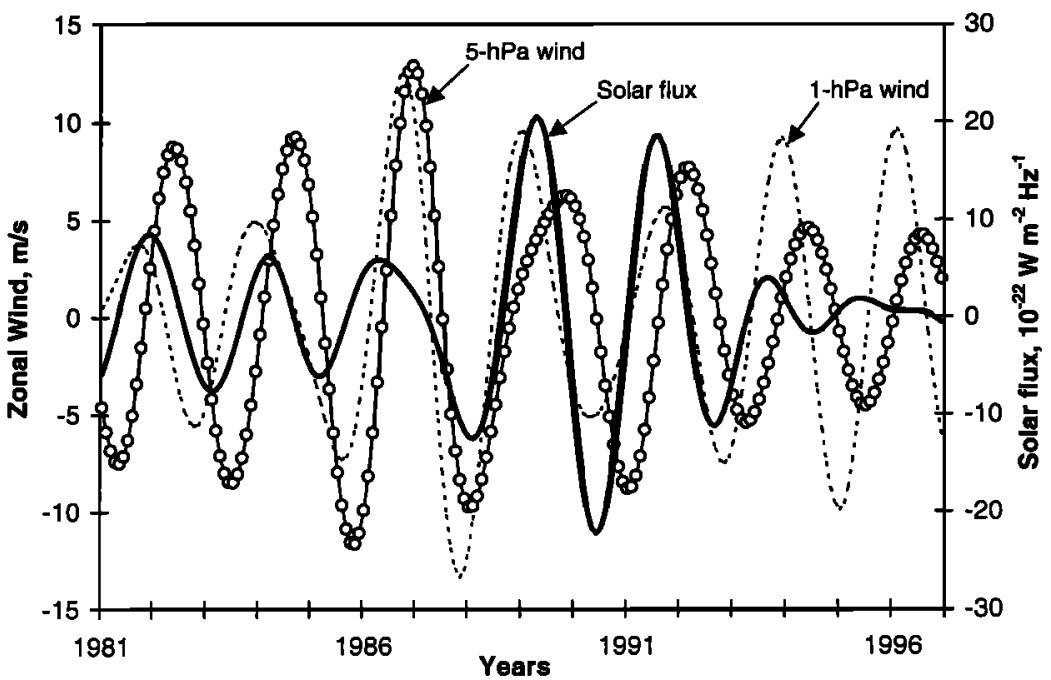

Figure 11. Band-pass-filtered (with frequency bounds corresponding to periods of 39 and 20 months) time series of the $10.7-\mathrm{cm}$ solar radio flux (thick solid line) and of the $1-\mathrm{hPa}$ (dashed line) and 5-hPa (thin solid line with circles) equatorial zonal wind.

the zonal wind response to the apparent solar forcing. Specifically, the phase lag increases from nearly zero at $1-2 \mathrm{hPa}$ to $\sim 1$ year at $10 \mathrm{hPa}$ and $\sim 2$ years at 50 $\mathrm{hPa}$. As coherency estimates are statistically significant, the corresponding phase estimates are significant as well [Jenkins and Watts, 1968]. Superposition of the curves of band-pass-filtered time series of the 10.7$\mathrm{cm}$ solar radio flux and of the equatorial zonal wind, where the QBO signal in both time series has been isolated, also confirms that the delay of the apparent stratospheric response after a solar flux perturbation on the QBO timescale increases with decrease of altitude (Figure 11). The superposed curves of the 10.7$\mathrm{cm}$ solar radio flux and of the 1- and 2-hPa zonal wind demonstrate a nearly inphase relationship. Such a relationship would be consistent with a direct modulation of the QBO in the upper stratosphere, where radiative and photochemical effects of solar ultraviolet variations are most pronounced. Some observational evidence for significant (4-7\%) solar cycle variations of upper stratospheric ozone amounts have been reported by Hood et al. [1993], Chandra and McPeters [1994], and McCormack and Hood [1996]. Taking into account that the amplitude of the solar 25-30-month oscillation changes significantly from solar minimum to maximum (Figure 6 ), one can suggest that any decadal variation of the QBO may be caused, at least in part, by a decadal modulation of the influence of the $25-30$-month solar oscillation on the equatorial zonal wind. However, a detailed model of the QBO that includes the effect of solar forcing at an upper boundary would be needed to test this possibility.

\section{Composite Analysis of the Equatorial Zonal Wind}

In the present section, we carry out a composite anal$y$ sis of the equatorial westerlies and easterlies in order to find possible changes in the vertical profile of zonal wind associated with 11-year solar forcing. For this purpose, band-pass-filtered data of the 10 - to $70-\mathrm{hPa}$ equatorial zonal wind, which have already been analyzed in section

Table 1 Duration of Selected QBO Phases During Four Solar Cycles.

Solar Cycle Maxımum / Mınımum

\begin{tabular}{|c|c|c|c|c|c|c|c|}
\hline $\begin{array}{l}\text { Solar } \\
\text { Act!vity }\end{array}$ & $\begin{array}{l}\text { QBO } \\
\text { Phase }\end{array}$ & Group & $1957-1960 / 1962-1965$ & $1967-1970 / 1974-1977$ & $1979-1982 / 1984-1987$ & $1989-1992 / 1994-1997$ & $\begin{array}{c}\text { Duration, } \\
\text { months }\end{array}$ \\
\hline Maxımum & westerly & 1 & Oct 1958 to Sept 1960 & Apnl 1968 to Sept 1970 & July 1979 to Jan 1982 & July 1989 to Feb 1992 & 29.3 \\
\hline Maximum & westerly & 2 & Nov 1960 to Feb. 1963 & Aug 1970 to Sept. 1972 & Jan. 1982 to June 1984 & Dec. 1991 to May 1994 & 28.5 \\
\hline Maximum & easterly & 1 & Oct 1957 to Oct. 1959 & July 1969 to Sept. 1971 & May 1978 to Nov. 1980 & Sept. 1990 to Apnl 1993 & 28.8 \\
\hline Maxımum & easterly & 2 & Nov 1959 to Nov. 1961 & Aug 1971 to Sept. 1973 & Oct. 1980 to March 1983 & March 1993 to June 1995 & 27.3 \\
\hline Minimum & westerly & 1 & Dec 1962 to Sept 1965 & Sept 1974 to March 1977 & June 1984 to Feb 1987 & May 1994 to July 1996 & 31.3 \\
\hline Minimum & westerly & 2 & Aug 1965 to Apnl 1968 & March 1977 to Aug 1979 & Jan 1987 to Aug 1989 & July 1996 to July 1998 & 30.0 \\
\hline Minımum & easterly & 1 & Oct 1961 to May 1964 & Aug 1973 to Dec 1975 & March 1983 to Sept. 1985 & June 1995 to July 1997 & 29.5 \\
\hline Mınımum & easterly & 2 & March 1964 to Dec 1966 & Dec. 1975 to May 1978 & Sept 1985 to May 1988 & July 1997 to July 1999 & 305 \\
\hline
\end{tabular}



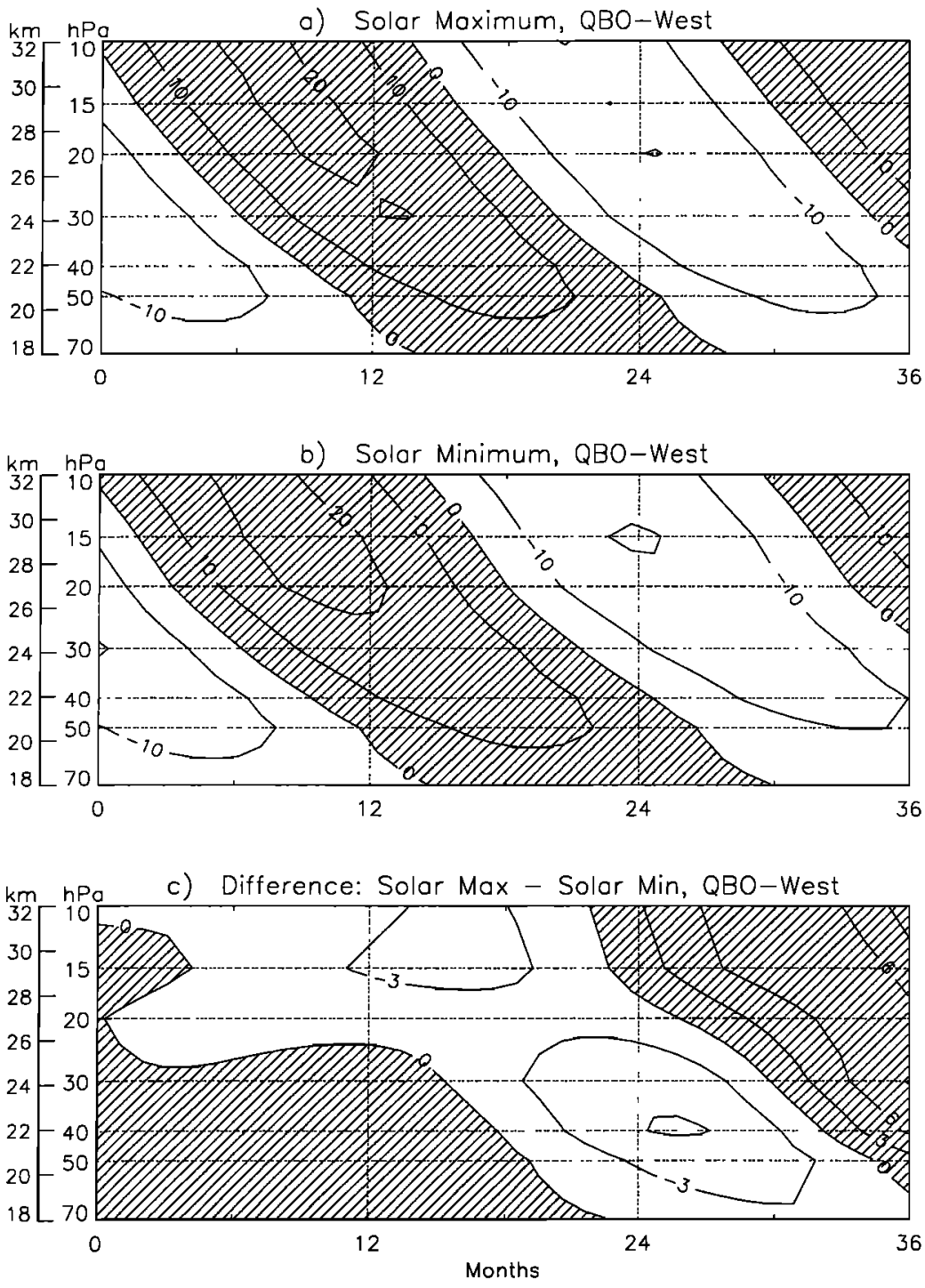

Figure 12. Mean vertical cross section of the westerly phase (hatched area) of the band-passfiltered (20-39 months) equatorial zonal wind for (a) solar maximum conditions and (b) solar minimum conditions. (c) represents the difference between Figures 12a and 12b. Eight cases of the westerly phase for solar minimum and for solar maximum conditions are used (Table 1). In all three plots the "zero" point of the westerly phase starts from $10 \mathrm{hPa}$.

5 , were divided into periods of maximum and minimum phases of the 11-year solar cycle according to the values of the $10.7-\mathrm{cm}$ solar radio flux. Data representing four solar maxima and four solar minima were analyzed here (Table 1). For each solar extremum, two westerly and two easterly phases of the equatorial zonal wind, each starting from the $10-\mathrm{hPa}$ level and ending at the 70-hPa level, were considered. The QBO phases were divided into two groups, as shown in Table 1. Group 1 represents those phases of the equatorial zonal wind which occurred either in the beginning of a given solar extremum or in the vicinity of its maximum. Group 2 represents those phases of the equatorial zonal wind which took place when a solar extremum was already in its declining phase. Thus cases belonging to the latter group are characterized by a 1-2-year phase lag after a corresponding solar extremum.

Figures 12 and 13 show the mean profiles of the westerly (Figure 12, hatched area) and easterly (Figure 13, open area) phases of the band-pass-filtered equatorial zonal wind under solar rnaximum conditions (Figures 12a and 13a) and under solar minimum conditions (Figures $12 \mathrm{~b}$ and $13 \mathrm{~b}$ ). The mean profiles were obtained by averaging eight westerly or easterly QBO phases (Table 1). For such averaging, the eight westerly or easterly phases of the zonal wind were aligned in such a way that they all started from the same "zero" point at 10 $\mathrm{hPa}$. Figures 12 and 13 represent the mean cross sections of the westerly and easterly phases from $10 \mathrm{hPa}$ ("zero" point) to $70 \mathrm{hPa}$ (ending point). When compar- 
ing Figures 12a and 12b (see also Table 1) one can see a difference in the duration of the westerly QBO phase between solar maximum and minimum conditions. The westerly phase in the lower stratosphere seems to last longer at solar minimum than at solar maximum (e.g., 30 months versus 28 months, at $70 \mathrm{hPa}$ ). The plot of the difference between solar maximum and solar minimum conditions (Figure 12c) shows that the largest difference in the duration of the westerly phase is observed in the lower stratosphere at the $40-50-\mathrm{hPa}$ levels.

The mean profile of the easterly phase of the bandpass-filtered equatorial zonal wind (Figure 13) also exhibits a slight difference between solar maximum and solar minimum conditions. Comparison of Figures 13a and $13 \mathrm{~b}$ shows that in the lower stratosphere the easterly phase tends to persist longer at solar minimum than at solar maximum (e.g., $29-30$ versus 27 months, at 70 $\mathrm{hPa}$ ). Figure $13 \mathrm{c}$ demonstrates that the largest changes in the equatorial easterlies between solar extrema are observed at levels of $30-50 \mathrm{hPa}$.
The plots in Figures 12 and 13 were obtained after an analysis of eight cases of the westerly phase and eight cases of the easterly phase under solar maximum and minimum conditions, respectively. Because of the interannual variability of the equatorial zonal wind the small number of the cases analyzed here does not allow one to consider the obtained differences between solar maximum and minimum conditions as a statistically robust result. However, apart from statistical criteria of significance, another useful approach to demonstrate plausibility of the obtained differences is a simple division of all cases into two groups as a test of whether the results obtained are consistent for both groups. The differences between solar maximum and minimum conditions in the mean profile of the equatorial westerlies for the two groups of cases, as described above, are shown in Figures 14a and 14b. The patterns in both plots show a prevalence of negative values (open area), which indicates that the duration of the westerly phase of the zonal wind is longer under solar minimum conditions

a) Solar Maximum, QBO-East

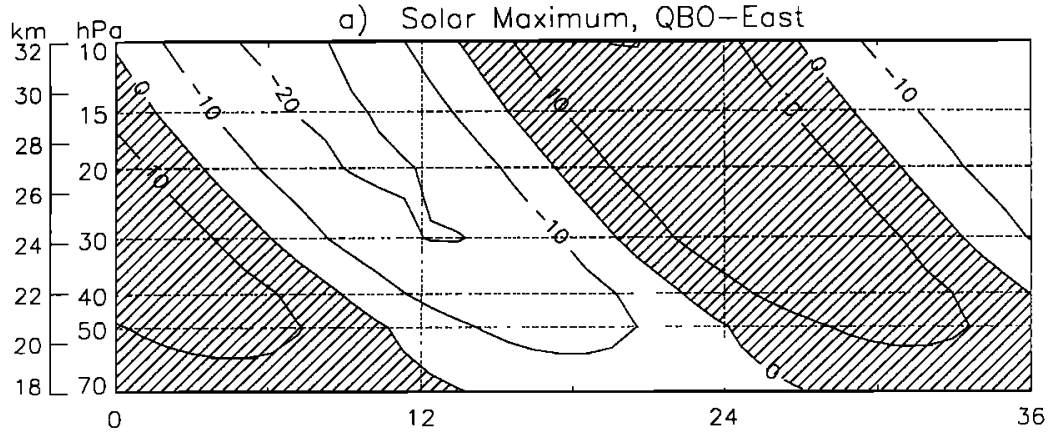

b) Solar Minimum, QBO-East
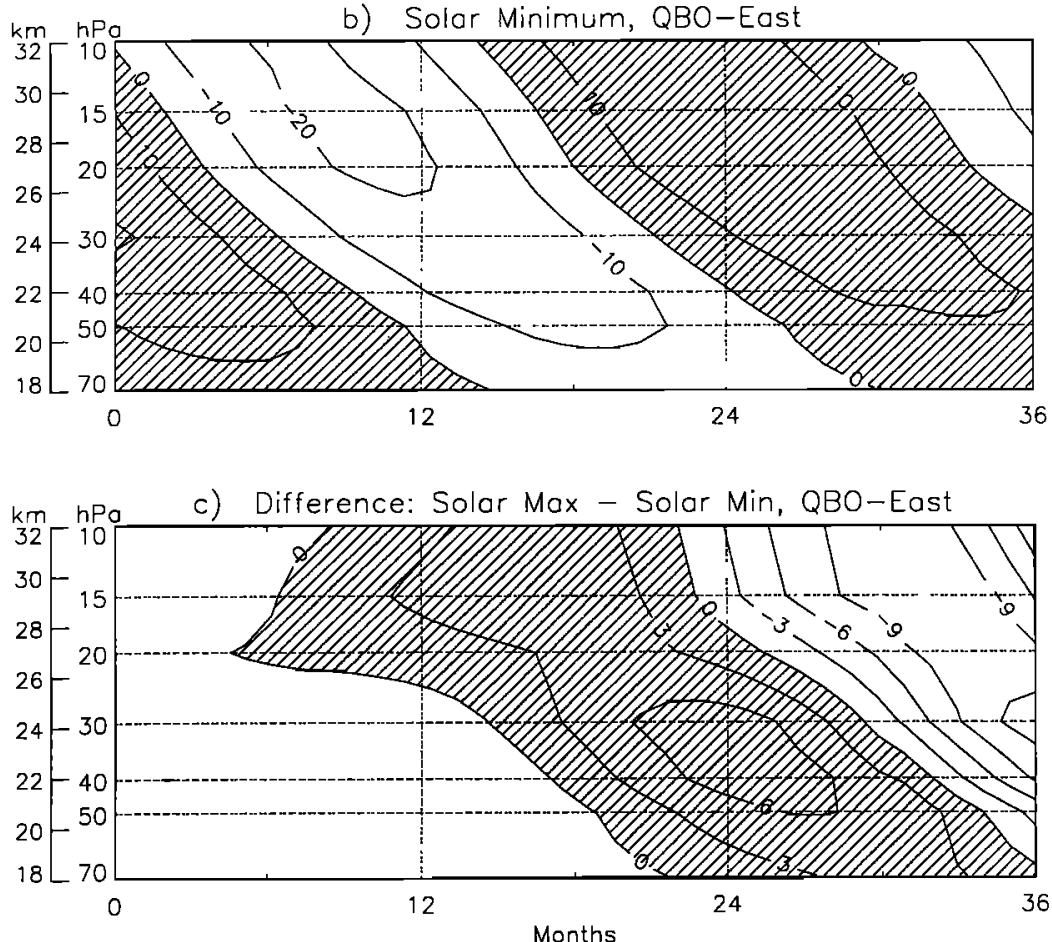

Figure 13. Same format as for Figure 12 but for the easterly phase (open area) of the equatorial zonal wind. 

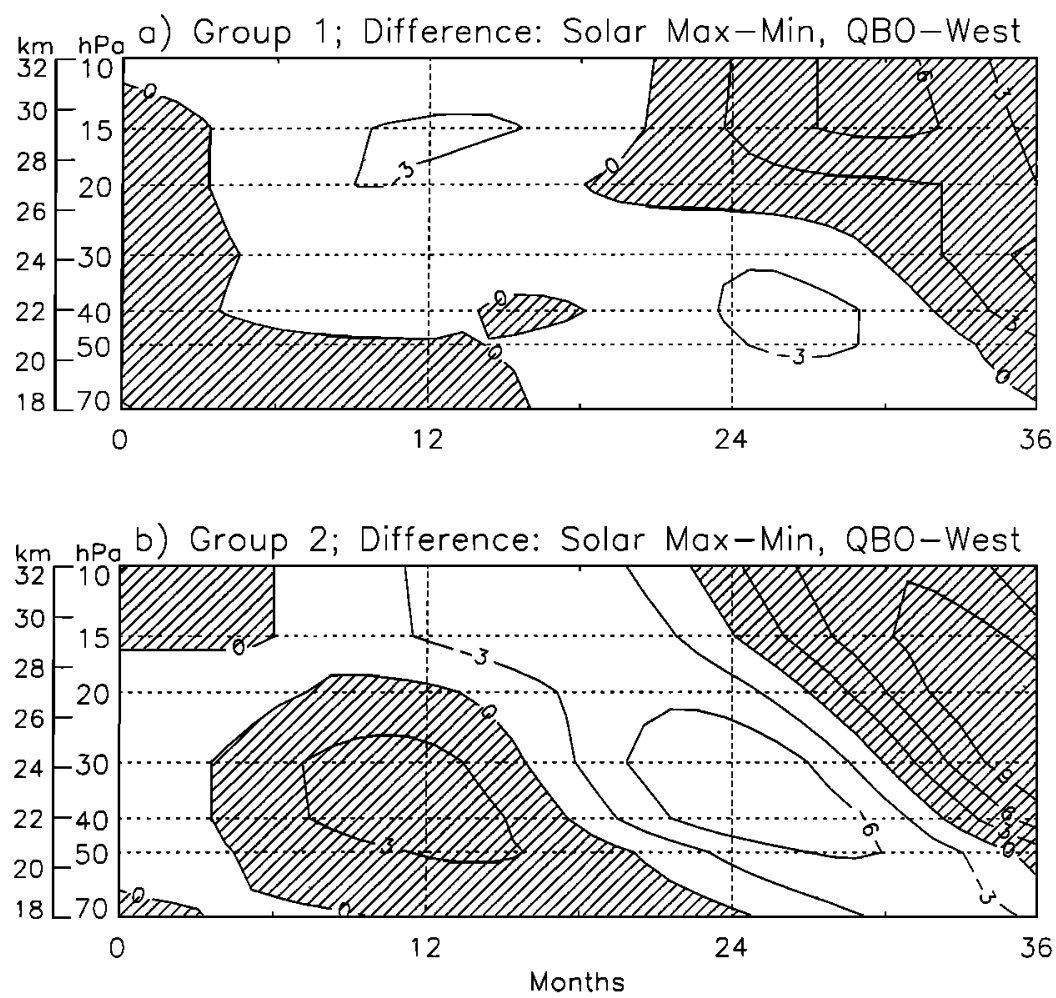

Figure 14. Difference between mean cross sections of the westerly phase of the band-pass-filtered equatorial zonal wind (with frequency bounds corresponding to periods of 39 and 20 months) under solar maximum and under solar minimum conditions. (a) First group: four cases at solar maximum and four cases at solar minimum when the westerly phase occurred in the beginning of a solar extremum or in the vicinity of its maximum; (b) Second group: four cases at solar maximum and four cases at solar minimum when the westerly phase occurred in the declining phase of a solar extremum. In both plots the "zero" point of the westerly phase starts from 10 $\mathrm{hPa}$.

than under solar maximum conditions. Especially, clear differences are observed for the second group of cases (Figure 14b), which represents the westerly phases during the period when solar extrema were in a phase of decline.

Figures 15a and 15b show the differences between solar maximum and solar minimum conditions for the band-pass-filtered easterly QBO phase, for each of two groups of cases. The patterns of positive values (hatched area) in both Figures $15 \mathrm{a}$ and $15 \mathrm{~b}$ indicate that the easterly phase tends to last longer during solar minimum than during solar maximum conditions. This is especially apparent in Figure 15b, showing that the difference between solar maximum and solar minimum conditions is largest in the lower stratosphere.

The approximate consistency between the results obtained separately for two groups of cases (Figures 14 and 15) appears to support a real difference in the profile of filtered equatorial westerlies and easterlies between extrema of the 11-year solar cycle, obtained from an analysis of all eight available cases (Figures 12 and 13). In addition, the evidence for largest differences in the lower stratospheric zonal wind during periods corresponding to a phase lag of $\sim 1-2$ years after solar ex- trema (Figures 14b and 15b) seems consistent with the results described in section 5 (and Figure 9), where we showed that the phase lag between possible solar forcing and the response of the zonal wind was $\sim 2$ years at $50 \mathrm{hPa}$.

\section{Conclusions}

In this study, we have reported cross-spectral evidence for a possible response of the equatorial quasibiennial wind oscillation to solar variability occurring at periods of 25-30 months. Because the solar flux variations at this period are larger near solar maxima than near solar minima, it is possible that this form of solar forcing contributes to the apparent decadal modulation of the QBO reported by Salby and Callaghan [2000]. As our analysis is a purely statistical one, we are not able to discern whether such a physical connection between solar variability and equatorial zonal wind on the 25-30-month timescale really takes place. However, the significant coherency at all stratospheric levels (Figures 7 and 8 ) and, especially, the steady increase of the phase lag from the upper to the lower stratosphere (Figures 9 and 10) seem to suggest that some physical solar- 

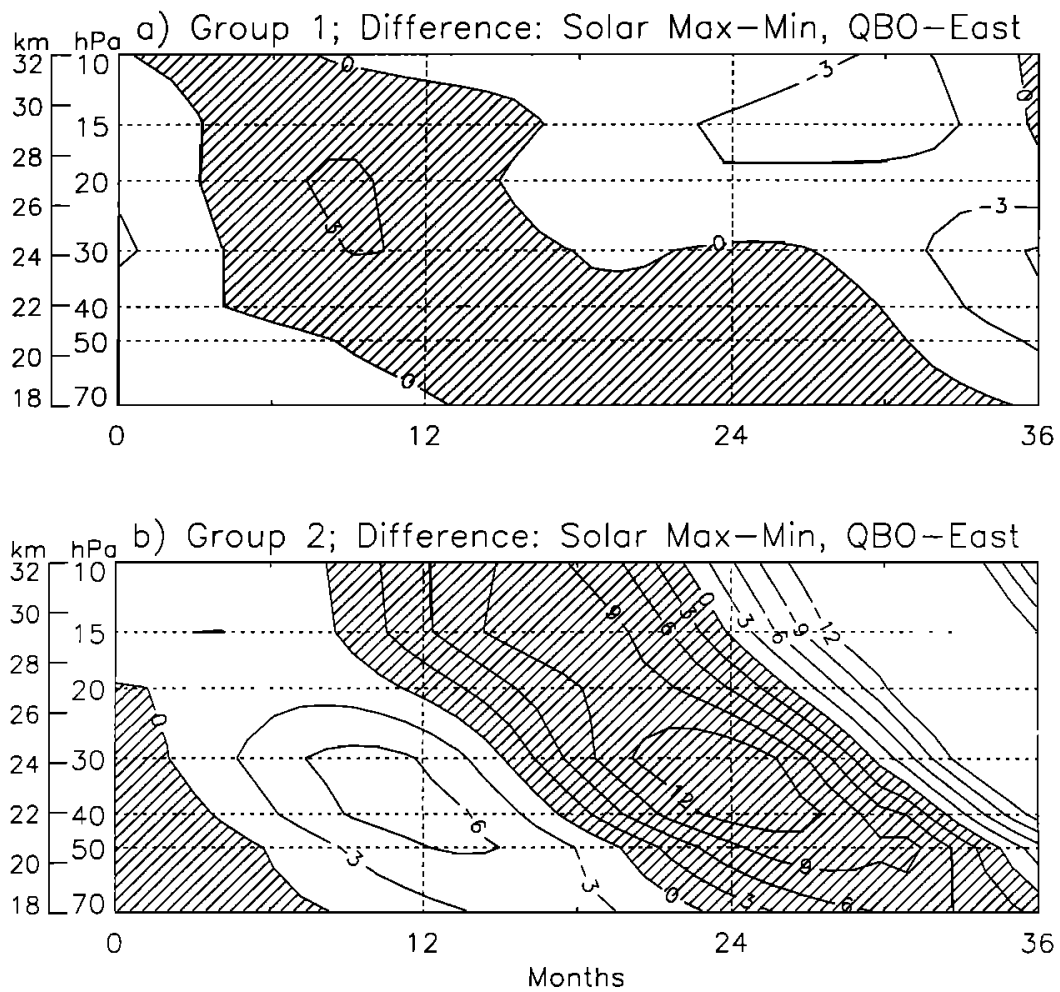

Figure 15. Same format as for Figure 14 but for the easterly phase of the equatorial zonal wind.

atmospheric interaction may occur on this timescale. In addition, composite analysis of the equatorial westerlies and easterlies yields apparent consistent differences between solar maximum and minimum conditions. The duration of both equatorial westerlies and easterlies in the lower stratosphere appears to be longer under solar minimum conditions than under solar maximum conditions (Figures 12 and 13). The latter is consistent with the result of Salby and Callaghan [2000], who noted that the number of months with the westerly and easterly QBO phases at $30 \mathrm{hPa}$ were different between solar maximum and minimum conditions.

If the hypothesized mechanism of solar-atmospheric interaction on the $25-30$-month timescale really takes place, then it must be complex, as reflected in Figure 2 where the decadal variation of the equatorial QBO is seen to be more pronounced in the lower stratosphere than in the upper stratosphere. In fact, although the solar and equatorial zonal wind oscillations on the 2530 -month timescale are nearly in phase in the upper stratosphere (1- and 2-hPa levels) (Figure 10), the amplitude of the zonal wind at these levels does not show any clear sign of the 11-year modulation (Figure 11). (It is noteworthy, however, that the upper stratospheric time series are very short, which makes obtaining reliable results for the upper stratosphere more difficult.) It is also worth mentioning that the solar-stratospheric correlations reported by Labitzke and van Loon [1988] are best if the QBO phase is taken at a level close to 40$50 \mathrm{hPa}$. Only these levels are characterized by a strong decadal variability of the equatorial QBO (Figure 2) and by a difference in the duration of the equatorial westerlies and easterlies between solar extrema (Figures 12-15). This implies an important role for stratospheric dynamics in the transmission of any solar-induced atmospheric response.

In a recent study by Soukharev and Labitzke [2000], evidence for an 11-year modulation of the middle stratospheric response to solar variability on the timescale of the Sun's rotation period ( $\sim 27$ days) was shown. The responses of the zonal mean geopotential height and temperature at 10 and $30 \mathrm{hPa}$ to those solar oscillations were found to be significantly different under solar maximum conditions than under solar minimum conditions. In combination the results of that study and of the present one suggest that the influence of the 11-year solar cycle on the atmosphere may not be limited to effects on the 11-year timescale, as it is usually considered, but may also include net effects on smaller timescales caused by an 11-year modulation of solar oscillations at shorter periods.

The statistical evidence of a possible interaction of the equatorial QBO with the 25-30-month solar oscillation on a decadal timescale, presented here, does not conclusively demonstrate a physical relationship between the Sun and the QBO. The amplitude of the 2530 -month solar oscillation is $\sim 2$ orders of magnitude less than that of the 11-year solar oscillation. If a decadal variation of this $25-30$-month solar oscillation really modulates the equatorial zonal wind, then it is unclear 
how so small a variation in solar output can lead to significant changes in the stratospheric zonal wind field. Near the equator the observed decadal modulation of the zonal wind requires a temperature change of 1-2 $\mathrm{K}$ [Salby and Callaghan, 2000]. However, it is unclear whether the decadal variation of the 25-30-month solar oscillation can produce even such relatively small temperature changes in the equatorial lower stratosphere. Intensive observational and modeling studies are needed to understand further the mechanism of how the signature of the solar cycle manifests itself in the behavior of the equatorial zonal wind.

Acknowledgments. The authors are grateful to B. Naujokat (Free University of Berlin) for the equatorial zonal wind data at 50,40,30, 20, and $10 \mathrm{hPa}$ and to $\mathrm{S}$. Zhou (NOAA/CPC) for geopotential height data at 5, 2, and 1 $\mathrm{hPa}$. This work was supported by a grant from the Solar Terrestrial branch of the National Science Foundation and by a grant from the NASA Solar Influences research program.

\section{References}

Balachandran, N.K., and D. Rind, Modeling the effects of the UV variability and the QBO on the troposphere/stratosphere system, I, The middle atmosphere, J. Clim., 8, 2058- 2079, 1995.

Baldwin, M., and T.J. Dunkerton, Observations and statistical simulations of a proposed solar cycle/QBO/weather relationship, Geophys. Res. Lett., 16, 863-866, 1989.

Baldwin, M.P., et al., The quasi-biennial oscillation, Rev. Geophys., in press, 2001.

Chandra, S., and R.D. McPeters, The solar cycle variation of ozone in the stratosphere inferred from Nimbus 7 and NOAA 11 satellites, J. Geophys. Res., 99, 20,665-20,671, 1994.

Ebdon, R.A., Notes on the wind flow at $50 \mathrm{mb}$ in tropical and subtropical regions in January 1957 and in 1958,Q. J. R. Meteorol. Soc., 86, 540-542, 1960.

Haigh, J.D., The role of stratospheric ozone in modulating the solar radiative forcing of climate, Nature, $370,544-$ 546,1994

Hamilton, K., A look at the recently proposed solar-QBOweather relationship, J. Clim., 3, 497-503, 1990.

Hines, C.O., A possible mechanism for the production of Sun-weather correlations, J. Atmos. Sci., 31, 589-591, 1974.

Holton, J.R., and R.S. Lindzen, An updated theory for the quasi-biennial cycle of the tropical stratosphere, J. Atmos. Sci., 29, 1976-1080, 1972.

Holton, J.R., and H.C. Tan, The influence of the equatorial QBO on the global circulation at $50 \mathrm{mb}, J$. Atmos. Sci., $37,2200-2208,1980$.

Holton, J.R., and H.C. Tan, The quasi-biennial oscillation in the Northern Hemisphere lower stratosphere, J. Meteorol. Soc. Jpn., 60, 140-148, 1982

Hood, L.L., The solar cycle variation of total ozone: Dynamical forcing in the lower stratosphere, J. Geophys. Res., 102, 1355-1370, 1997.

Hood, L.L., J.L. Jirikovic, and J.P. McCormack, Quasidecadal variability of the stratosphere: Influence of longterm solar ultraviolet variations, J. Atmos. Sci., 50, 39413958, 1993.

Jenkins, G.M., and D.G. Watts, Spectral Analysis and its Applications, 525 pp., Holden Day, San Francisco, 1968.
Kodera, K., Quasi-decadal modulation of the influence of the equatorial quasi-biennial oscillation on the north polar stratospheric temperatures, J. Geophys. Res., 98, 7245$7250,1993$.

Labitzke, K., Sunspots, the QBO, and the stratospheric temperature in the North polar region, Geophys. Res. Lett., 14, 535-537, 1987.

Labitzke, K., and H. van Loon, Associations between the 11-year solar cycle and the atmosphere, part 1, The troposphere and stratosphere in the Northern Hemisphere in winter, J. Atmos. Terr. Phys., 50, 197-206, 1988.

Lindzen, R.S., On the development of the theory of the QBO, Bull. Am. Meteorol. Soc., 68, 329-337, 1987.

Lindzen, R.S., and J.R. Holton, A theory of the quasibiennial oscillation, J. Atmos. Sci., 25, 1095-1107, 1968.

McCormack, J.P., and L.L. Hood, Apparent solar cycle variations of upper stratospheric ozone and temperature: Latitude and seasonal dependences, J. Geophys. Res., 101, 20,933-20,944, 1996.

Naito, Y., and I. Hirota, Interannual variability of the northern winter stratospheric circulation related to the QBO and solar cycle, J. Meteorol. Soc. Jpn., 75, 925-937, 1997.

O'Sullivan, D., and M.L. Salby, Coupling of the quasibiennial oscillation and the extratropical circulation in the stratosphere through planetary wave transport, J. Atmos. Sci., 47, 650-673, 1990.

Plumb, R.A., The interaction of two internal waves with the mean flow: Implications for the theory of the quasibiennial oscillation, J. Atmos. Sci., 34, 1847-1858, 1977.

Randel, W.J., Global atmospheric circulation statistics, 1000$1 \mathrm{mb}, N C A R$ Tech. Note $366+S T R, 256$ pp., Natl. Cent. for Atmos. Res., Boulder, Colo., 1992.

Reed, R.J., W.J. Campbell, L.A. Rasmussen, and D.J. Rogers, Evidence of downward-propagating, annual wind reversal in the equatorial stratosphere, J. Geophys. Res., $66,813-818,1961$.

Rind, D., and N.K. Balachandran, Modeling the effects of UV variability and the QBO on the troposphere-stratosphere system, part II, The troposphere, J. Clim., 8, 20802095,1995

Salby, M., and P. Callaghan, Connection between the solar cycle and the QBO: The missing link, J. Clim., 13, 26522662,2000

Shapiro, R., and F. Ward, A neglected cycle in sunspot numbers? J. Atmos. Sci., 19, 506-508, 1962.

Shindell, D., D. Rind, N. Balachandran, J. Lean, and P. Lonergan, Solar cycle variability, ozone, and climate, Science, 284, 305-308, 1999.

Soukharev, B.E., On the solar/QBO effect on the interannual variability of total ozone and the stratospheric circulation over northern Europe, J. Atmos. Sol. Terr. Phys., 61, 1093-1109, 1999.

Soukharev, B.E., and K. Labitzke, The 11-year solar cycle, the sun's rotation, and the middle stratosphere in winter, part I, Response of zonal means, J. Atmos. Sol. Terr. Phys., 62, 335-346, 2000.

Tung, K., and H. Yang, Global QBO in circulation and ozone, part II, A simple mechanistic model, J. Atmos. Sci., 51, 2708-2721, 1994.

van Loon, H., and K. Labitzke, The influence of the 11-year solar cycle on the stratosphere below $30 \mathrm{~km}$ : A review, Space Sci. Rev., 94, 259-278, 2000.

L. L. Hood and B. E. Soukharev, Lunar and Planetary Laboratory, University of Arizona, Tucson, AZ 85721-0092. (lon@lpl.arizona.edu; boris@lpl.arizona.edu)

(Received September 27, 2000; revised January 2, 2001; accepted January 19,2001 .) 